\title{
Cell-Cycle, Phase-Specific Activation of Maize streak virus Promoters
}

\author{
Krisztina Nikovics, ${ }^{1}$ Julietta Simidjieva, ${ }^{1}$ Adrian Peres, ${ }^{1}$ Ferhan Ayaydin, ${ }^{1}$ Taras Pasternak, ${ }^{1}$ \\ Jeffrey W. Davies, ${ }^{2}$ Margaret I. Boulton, ${ }^{2}$ Dénes Dudits, ${ }^{1}$ and Gábor V. Horváth ${ }^{1}$ \\ ${ }^{1}$ Institute of Plant Biology, Biological Research Centre, Hungarian Academy of Sciences, Szeged, Hungary; \\ 2John Innes Centre, Norwich Research Park, Norwich NR4 7UH, U.K. \\ Accepted 11 December 2000.
}

It is believed that geminiviral DNA replication is coupled to the cell-cycle regulatory complex of the plant cell and that the virus-early (complementary or $C$ sense) gene products REP and REPA may be able to manipulate the regulation of the cycle. In this study, we examined expression from the promoters of Maize streak virus (MSV) in transgenic maize plants and cells to determine whether they showed cell-cycle specificity. Histochemical staining of plant roots containing "long and short" C-sense promoter sequences upstream of the $G U S$ ( $\beta$-glucuronidase) reporter gene showed that promoter activity was restricted to the meristematic region of the roots and was enhanced by 2,4-dichlorophenoxy acetic acid (2,4-D) treatment. Analysis of reporter gene and cell-cycle-specific gene transcript levels coupled with flow cytometric data in synchronized transgenic maize cells revealed that all of the MSV promoters showed cell-cycle specificity. The coat protein gene promoter showed highest activity in early G2, whereas the $\mathrm{C}$-sense promoter sequences produced two peaks of activity in the $S$ and $G 2$ cell-cycle phases.

Additional keyword: transcripts.

Geminiviridae is a family of plant DNA viruses with singlestranded circular DNA genomes encapsidated in particles with unique twinned subunits. Maize streak virus (MSV) is the type species of the genus Mastrevirus (Padidam et al. 1997). MSV has a monopartite genome and is transmitted by the leafhopper Cicadulina mbila to most members of the Poaceae spp. (Lazarowitz 1988; Lazarowitz 1992; Mullineaux et al. 1984; Palmer et al. 1998). A double-stranded replicative form of the viral DNA serves as the transcription template and the viral genes are likely transcribed by the host RNA polymerase II. Bidirectional promoters are located in the large intergenic region (LIR) and polyadenylation signals can be found in the small intergenic region (SIR) of the viral genome (Fig. 1A) (Lazarowitz 1992; Morris-Krsinich et al. 1985; Mullineaux et al. 1984; Wright et al. 1997). Two mRNA species are transcribed from the virion (V)-sense DNA strand. The movement protein (MP) is probably translated from the less abundant, longer mRNA, whereas the coat protein $(\mathrm{CP})$ is likely synthe-

Corresponding author: D. Dudits;

E-mail: dudits@nucleus.szbk.u-szeged.hu

Current address of G. V. Horváth: Institut des Sciences Végétales, CNRS, Avenue de la Terrasse, 91198 Gif sur Yvette, France. sized from the shorter, abundant mRNA species (MorrisKrsinich et al. 1985; Wright et al. 1997). The MP is important for viral cell-to-cell movement (Boulton et al. 1993; Dickinson et al. 1996; Kotlitzky et al. 2000), and the CP has been implicated in intercellular and intracellular movement (Boulton et al. 1989; Boulton et al. 1993; Lazarowitz et al. 1989; Liu et al. 1997; Liu et al. 1999; Liu et al. 2000). Expression of the $\mathrm{V}$-sense genes $(M P$ and $C P$ ) appears to be tightly regulated, involving differential transcription initiation points and differential splicing at an intron within the MP (Wright et al. 1997).

The MSV replication-associated proteins REP and REPA are expressed from the complementary (C) strand via differently spliced mRNA (Wright et al. 1997). The spliced transcript produces the $\mathrm{C} 1-\mathrm{C} 2$ fusion protein (REP). The differential C-sense transcript splicing is typical for the mastreviruses that infect cereals and other grasses (e.g., Wheat dwarf virus [WDV] and Digitaria streak virus) (Dekker et al. 1991; Mullineaux et al. 1990). The REP protein was shown to be the only protein required for replication of WDV in dividing Triticum monococcum cell cultures (Schalk et al. 1989).

Little is known about promoter functions of the mastreviruses. The LIR and DNA sequences upstream of the $C P$ gene of MSV were proven to be sufficient for transient expression of a reporter gene in maize protoplasts (Fenoll et al. 1988). A similar promoter construct was shown to direct vascularspecific $\beta$-glucuronidase (GUS) expression in the root, stem, leaf, and floral organs of transgenic rice (Oryza sativa L.) plants, although histochemical staining showed that the $C P$ gene promoter also was active in cells of regenerating callus (Mazithulela et al. 2000). Transient assays of chloris striate mosaic virus promoters and the WDV "virion-sense" promoter also have been carried out with cell cultures or immature embryo explants (Gooding et al. 1999; Zhan et al. 1993). The recalcitrance of cereals to regeneration has precluded further characterization of these promoters.

In this work, we demonstrate that MSV promoters can regulate reporter gene expression in transgenic maize in a cellcycle, phase-specific manner. Both $\mathrm{C}$-sense promoter constructs tested are active in $\mathrm{S}$ and $\mathrm{G} 2$, and the $C P$ gene promoter shows the highest activity in the early G2 cell-cycle phase.

\section{RESULTS}

MSV genome elements as promoters in suspension culture cells and in the root meristem of transgenic maize plants.

Maize protoplasts were transformed with the promoter element constructs prCP, prREPS, or prREPL (Fig. 1B). The 
prCP construct contains the MSV LIR and the DNA sequence upstream of the translation initiation codon of the $C P$ gene and thus includes the $M P$ sequence (Fig. 1A). Mutational analysis has shown that this region contains motifs important for activity of the CP promoter (Fenoll et al. 1988; Fenoll et al. 1990). The prREPS construct (Fig. 1B) contains a short version of the $\mathrm{C}$-sense promoter, which encompasses the $M P$ sequence and the LIR, but cloned in the reverse orientation compared with the $C P$ promoter. The prREPL construct (Fig. 1B) contains an extended version of the prREPS promoter to evaluate the effect of other MSV sequences on the activity of the promoter. This construct harbors most of the MSV genome; only the sequence encoding RepA is lacking. Several independent transgenic maize cell lines were obtained following direct DNA uptake into protoplasts, and the presence of the introduced genes were confirmed by Southern blot hybridization analysis (data not shown).

A

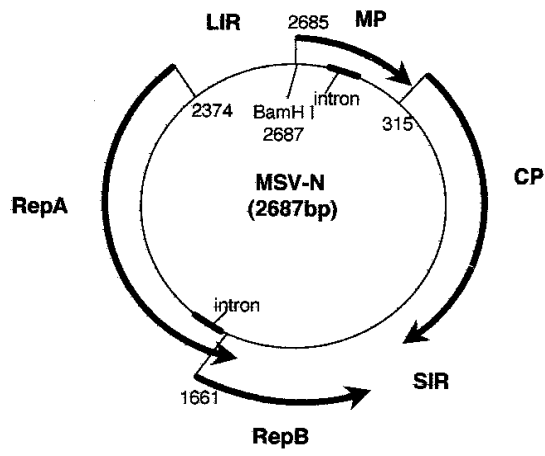

B

prcp

prREPL

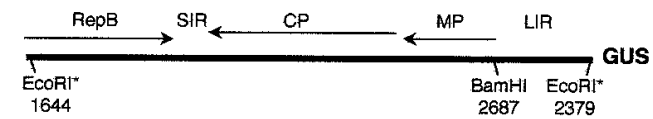

Fig. 1. The genome organization of the Nigerian strain of Maize streak virus (MSV-N) and the schematic representation of the MSV sequences included in the chimeric constructs used for maize cell transformation. A, Genome organization of MSV-N. Arrows indicate viral open reading frames (ORFs) or genes and the direction of their transcription. The replication-associated protein, REP, is produced from the replication associated protein A (REPA) and B (REPB) ORFs via a spliced transcript. MSV genome size (in base pairs) and coordinates are according to Mullineaux et al. (1984). LIR: large intergenic region; SIR: small intergenic region; MP: movement protein; $\mathrm{CP}$ : coat protein. REPB is unlikely to be produced. B, Schematic representation of the MSV sequences included in the chimeric constructs used for maize cell transformation. Plants were transformed with vectors containing transcriptional fusions of one of the viral promoters of MSV with the coding region of the $\beta$-glucuronidase (GUS) gene. prCP and prREPS constructs contain 618 bp of the MSV genome between MSV coordinates 2,379 and 295; prREPL contains 1,969 bp $(2,379$ to 1,644$)$. RepB protein is unlikely to be produced from prREPL; other protein coding regions are likely to be functional. * = restriction sites created by polymerase chain reaction amplification of the MSV DNA; $* *=$ sites derived from pBluescript+.
For each of the promoters, there was considerable variation in GUS activity between the transgenic lines (Table 1). It was possible, however, to identify a difference in the activity of the promoters in the transgenic maize cell suspensions. As shown in Table 1, the GUS activity obtained in all five lines transformed with prCP was higher than that obtained with prREPS, and only one of the lines transformed with prREPL (prREPL 3) produced GUS activity as high as that seen in any prCP line. Furthermore, three of the four lines transformed with prREPL had higher GUS activity than that seen in the prREPS lines. Thus, the lowest activity was obtained in cells expressing the prREPS construct and the highest activity was seen with prCP (Table 1).

Roots of the maize plantlets transformed with the prREPS construct were assayed by histochemical staining for GUS activity (Fig. 2A and B). In all cases, staining was observed in the root tip and the lateral root primordia, and young root tips stained more strongly than older ones. The roots of transgenic plants harboring prREPL showed a very similar pattern (Fig. $2 \mathrm{C}$ and $\mathrm{D}$ ), although staining always was stronger in these lines. No staining was seen in the roots of nontransformed (control) plants (data not shown). Thus, staining in the meristematic tissues indicated that the MSV C-sense promoters are active in dividing cells. No GUS activity could be detected in leaves or shoots of plants in any of the lines transformed with prREPS and prREPL. Either the activity of the promoters was too low to be assessed in the pigmented parts of the plants or the promoters are not active in vegetative tissue.

\section{Hormonal induction of cell division activates the MSV promoters.}

A synthetic auxin (2,4-dichlorophenoxyacetic acid or 2,4-D) can activate the plant-cell division cycle through a complex signaling pathway (Dudits et al. 1993). To determine whether 2,4-D treatment could influence expression from the MSV promoters, roots of maize plantlets transgenic for the prREPS or prREPSL construct were treated with the hormone. The roots were assayed for bromodeoxyuridine (BrdU) incorporation, and the same roots were used for histochemical assay of GUS activity. Roots transformed with prREPL showed increased promoter activity following 2,4-D treatment (seen as more intense staining; compare Fig. 2C and E) and, in parallel, increased division frequency in the pericycle cells of the root tip was seen (Fig. 2F) compared with the untreated roots (not shown). Observation of the roots at higher magnification revealed that the small, dense isodiametric cells formed around the vascular tissue following 2,4-D treatment exhibited strong DNA replication activities (Fig. $2 \mathrm{G}$ and $\mathrm{H}$ ). In some roots treated with 2,4-D, strong GUS activity could be observed in the pericycle cells, even though no other part of the root tip was labeled (Fig. 2I). Possibly, 3-day incubation on 2,4-D reactivates the cell cycle in pericycle cells and may reflect an early step in lateral root formation. In approximately $30 \%$ of the roots examined, the small, isodiametric cells were not observed, but BrDU labeling and GUS activity were both increased. In young roots, auxin treatment resulted in increased numbers of cells labeled with BrdU and showing GUS activity, whereas less response was seen in older roots. Similar responses were obtained with both concentrations of the auxin, indicating that maize root cells are responsive but quite tolerant to 2,4-D treatment. Incubation of plantlets transformed 
with prREPS in the presence of 2,4-D resulted in similar increases in cell-division frequency and GUS activity (data not shown). These data suggest a strong correlation between the level of BrdU incorporation and GUS activity and that the MSV C-sense promoter is active in cycling cells.

Transgenic maize cell suspensions were used to determine whether auxin treatment affects the activity of MSV promoters in undifferentiated cells. Cells were incubated in medium supplemented with 2,4-D, and samples were taken at 1, 3, and $48 \mathrm{~h}$ postaddition. Untreated samples were processed in parallel. There was no significant difference in GUS activity between the prCP-transformed cells in the presence or absence of the hormone at 1 or $3 \mathrm{~h}$ after the addition of 2,4-D (Fig. 3), indicating that 2,4-D did not immediately affect $C P$ gene promoter activity. After $48 \mathrm{~h}$ incubation, the GUS activity was approximately twofold higher in the 2,4-D-treated samples. This delayed response could reflect increased cell-cycle activation in 2,4-D-treated cells. Approximately twofold increases in promoter activity were obtained $48 \mathrm{~h}$ after 2,4-D treatment of cells transformed with prREPS or prREPL.

\section{MSV promoters are active in different cell-cycle phases.}

To investigate further the potential cell-cycle, phasespecific activation of MSV promoters, the transgenic maize cell suspensions were cultured in hydroxyurea. With the use of this method, approximately $47 \%$ of the suspension cells were blocked in $\mathrm{S}$ phase, resulting in a partial synchrony in cell-cycle progression after the removal of the hydroxyurea (Fig. 4B), and the partial synchrony was maintained during the tested period. The cell-cycle phases of the cultures were identified by a combination of flow cytometry and maize histone $H 4$ (S-phase specific) and cyclin B1 (G2- to M-phase specific) gene transcripts (Fig. 4). The changes in the transcript levels of the GUS reporter gene also were monitored. In prCP transformed cell lines, the GUS transcript was visible from $2 \mathrm{~h}$, but gradually increased to reach a maximum of $8 \mathrm{~h}$ after the removal of the hydroxyurea. This latter time point occurred after the maximum expression of the $\mathrm{H} 4$ gene and prior to the appearance of the cyclin B1 transcripts. The flow cytometric data show that $9 \mathrm{~h}$ after removal of the hydroxyurea, more than $50 \%$ of cells were in G2 phase (Fig. 4B). Taken together, these data suggest that the MSV CP gene promoter is most active in early G2 cell-cycle phase but also functions during $\mathrm{S}$ phase.

Synchronization of a transgenic maize cell suspension transformed with the prREPL construct (Fig. 5) allowed us to examine bidirectional transcription from this MSV promoter. The expression (transcription) of the $C P$ was monitored with a $C P$-specific probe, whereas the expression from the prREPL promoter could be assessed with a $G U S$-specific probe. The $C P$ gene expression again reached its maximum level $8 \mathrm{~h}$ after the removal of hydroxyurea. As in the previous experiment, host gene expression and flow cytometric data suggested that the majority of cells were in either S or early G2 phase (Fig. $5 \mathrm{~A}$ to $\mathrm{C}$ ). Thus, cell-cycle-regulated expression from the $C P$ gene promoter appears to be maintained, irrespective of whether the template is the prCP promoter fragment or the prREPL construct.

When the activity of the $\mathrm{C}$-sense promoter present in prREPL was assessed by densitometric analysis of the $G U S$ mRNA level, two separate peaks were seen during the 26-h sampling period (Fig. 5B). The first maximum was reached 2 $\mathrm{h}$ after removal of the hydroxyurea, and a second peak was detected after $14 \mathrm{~h}$. Flow-cytometric and cell-cycle-specific host gene expression data suggest that the first peak corresponds to early $S$ phase, whereas the second peak is in late G2 phase. Our results indicate that MSV bidirectional promoter activity is regulated in a cell-cycle, phase-specific manner; the $\mathrm{C}$-sense gene expression is first seen in early $\mathrm{S}$ phase, followed by $\mathrm{V}$-sense expression (of the $C P$ gene) in early $\mathrm{G} 2$ phase. A second period of $\mathrm{C}$-sense gene expression occurs in late $\mathrm{G} 2$ phase.

\section{DISCUSSION}

Previous studies have shown that host cell transcription machinery is used for geminivirus gene expression (HanleyBowdoin et al. 1999), and our results support this assumption. Most studies of geminivirus promoter activity with transgenic plants have concentrated on the characteristics of begomovirus promoters, which seem to be active mainly in the vascular tissue. For example, in tobacco plants transformed with the $G U S$ gene under the control of the $C P$ promoter of Pepper huasteco virus, GUS activity was seen in vascular tissues close to the lateral buds and the apical region of the stem but not in leaves (Ruiz-Medrano et al. 1999). The CP promoter of Tomato golden mosaic virus (TGMV) showed phloemspecific activity in transgenic tobacco plants in the absence of other viral proteins (Sunter and Bisaro 1997), although mesophyll expression was activated when the viral AC2 product (transcriptional activator protein) was coexpressed in the tissues. The African cassava mosaic virus (ACMV) CP promoter, however, showed low-level constitutive expression in the absence of other ACMV proteins (Hong et al. 1996). In contrast, the MSV CP promoter produced tissue-specific expression in transgenic rice plants. The activity was restricted to the vascular tissue of the root, stem, leaf, and floral organs, but also was seen in regenerating callus cells (Mazithulela et al. 2000). In the current study, the MSV CP promoter also was active in dividing suspension culture cells.

Table 1. $\beta$-glucuronidase (GUS) activity in transgenic maize callus lines.

\begin{tabular}{lcc}
\hline Samples $^{\mathbf{a}}$ & GUS activity $^{\mathbf{b}}$ & Mean value \pm standard deviation \\
\hline Control $^{\mathrm{c}}$ & 125.0 & \\
PrCP (1) & $1,170.0$ & $1,113.5 \pm 227.8$ \\
PrCP (2) & $1,215.0$ & \\
PrCP (3) & $1,410.0$ & \\
PrCP (4) & 848.1 & $539.4 \pm 202.0$ \\
PrCP (5) & 923.8 & \\
PrREPS (1) & 282.5 & \\
PrREPS (2) & 518.1 & \\
PrREPS (3) & 771.9 & \\
PrREPS (4) & 585.0 & \\
PrREPL (1) & 818.1 & \\
PrREPL (2) & 698.7 \\
PrREPL (3) & $1,013.0$ \\
PrREPL (4) & 898.1 \\
\hline a Fluorimetric GUS assays were done as described by Jefferson et al. \\
(1987). Callus from independent transgenic lines was sampled 2 weeks \\
after subculture. The callus lysate was prepared immediately after \\
sampling. The line number for each construct is shown in parenthesis. \\
b pmol MU per mg of protein per h; duplicate samples were used for \\
each assay. \\
c Nontransformed He/89 culture.
\end{tabular}





Fig. 2. Histochemical localization of $\beta$-glucuronidase (GUS) activity in 1-month-old roots of maize plantlets transformed with the Maize streak virus promoter-GUS constructs $\mathbf{A}$ and $\mathbf{B}$, prREPS or $\mathbf{C}-\mathbf{E}$, prREPL. A and C, Root tips and A, B, and D, lateral root primordia from transformed plants after staining for $16 \mathrm{~h}$. Tissues were stained for $16 \mathrm{~h}$ and then observed under a stereomicroscope. Roots from a plantlet transformed with prREPL and treated with $1 \mathrm{mg}$ of 2,4-dichlorophenoxy acetic acid per liter 2 months after shoot regeneration were assessed for $\mathbf{E}$, GUS activity and $\mathbf{F}$, bromodeoxyuridine (BrdU) incorporation. F and $\mathbf{H}$, Fluorescence representative of BrdU incorporation into nuclei was visualized by fluorescence microscopy. To identify tissue and cell types the root shown in $\mathbf{F}$, was examined at higher magnification by $\mathbf{G}$, dark-field microscopy. Small, dense isodiametric cells were visible around the vascular tissue (arrowed in $\mathbf{G}$ ) show strong BrdU incorporation (green spots, arrowed in $\mathbf{H}$ ). Nuclei were identified by 4,6-diamidine-2phenylindole staining (red fluorescence). Bar: $100 \mu \mathrm{m}$; cc: cortical cells; vt: vascular tissue; rt: root tip; lrp: lateral root primordium. 
Expression from the geminivirus C-sense ("early gene") promoters in transgenic plants has been studied little. In the current work, two MSV $C$-sense promoter constructs were created to allow preliminary study of potential cis-regulatory elements present within the MSV promoters. Terada et al. (1995) showed that hexamer (ACGTCA) and octamer (CGCGGATC) motifs in the wheat histone $H 3$ gene promoter conferred meristem-specific expression. Motifs conferring similar expression characteristics have been identified in the maize histone $H 3$ and the cauliflower mosaic virus (CaMV) $35 \mathrm{~S}$ promoters (Atanassova et al. 1998; Benfey et al. 1990) as well as in the enhancer region of the bacterial octopine synthase promoter (Bouchez et al. 1989). Computer-assisted analysis of the MSV genome showed the presence in the Csense strand of a region similar to the octamer motif (GGCGGATT; coordinates 2,459 to 2,452) in the upstream activating sequence (UAS) of the MSV LIR and a hexamer motif (coordinates 564 to 559) in the $C P$ gene sequence (Morozov et al. 1994). The latter motif is present only in the prREPL construct. Both of the MSV C-sense promoters ("short," present in prREPS, and "long," in prREPL) were active only in dividing cells in the roots of transgenic maize plantlets. The long promoter, however, produced higher GUS activity in the roots of these plants, which suggests the presence of positive regulatory cis-elements outside the LIR and MP gene. Terada et al. (1995) found that the octamer motif in the wheat $H 3$ gene promoter was responsible for meristemspecific gene expression, whereas the hexamer motif acted as a positive regulatory element. In the current study, only the long C-sense promoter contained both cis elements and, therefore, our data are compatible with these functions, although further work is required to identify the sequences that confirm enhanced expression. The similarity in distribution of GUSpositive cells and BrdU-labeled cells further supports our conclusion that the $\mathrm{C}$-sense promoters are active in dividing cells of the root tip, the lateral root primordium, and certain cells of the vascular tissue, especially following auxin treatment.

Auxin plays an important role in the differentiation of vascular tissue (Aloni 1987), regulation of apical dominancy (Cline 1994), cell elongation, and cell division (Cleland 1987; Evans 1984). Although the exact role is not yet known, auxin has a function in lateral root development (Webster and Radin 1972). During this process, the first step is the reactivation of the pericycle cells, followed by the differentiation of the lateral root primordium, and finally the formation of the meristem in the tip of the young lateral root. Our results indicate that the addition of 2,4-D to the tissue culture medium could increase the cell-division activity of pericycle cells surrounding the root vascular cylinder of maize plantlets within 3 days, and that this activation is greater in young roots and cells close to the root tip. These findings are in agreement with data previously reported for 2,4-D-treated carrot hypocotyls (Guzzo et al. 1995). Furthermore, Alizadeh and Mantell (1991) reported the decreased potential to induce cell division in aged tissues of Solanum aviculare. In our experiments, we also did not observe any effects on the morphology or cell division in fully differentiated lateral roots subjected to 2,4-D treatment. We suggest, therefore, that the 2,4-D treatment affected the early stage of maize lateral root formation, resulting in the activation of cell division in the pericycle, and that the changes in the MSV promoter function are linked to this acti- vation. Additional experimentation is required to determine whether this is the case or whether the viral promoters respond to the auxin per se.

Plant cell growth and development depend upon continuous cell proliferation, which is restricted to meristems. Some geminiviruses are phloem restricted (Abouzid et al. 1988; Sanderfoot and Lazarowitz 1996) and therefore can take advantage of meristematic activity of precambial cells, whereas others, including MSV, have been detected outside the vascular system in differentiated cells (Lucy et al. 1996; Nagar et al. 1995; Rushing et al. 1987). The geminivirus replicative cycle relies on host cell factors. Because most of the replicative factors are present in proliferating cells, geminivirus infection is believed to induce a cellular state permissive for viral DNA replication (Gutierrez 2000). Whether this is done by inducing cells to enter the $\mathrm{S}$ phase or to provide some specific S-phase function(s) is not yet clear.

Synchronized cell suspensions provide useful tools to study cell-cycle control of gene expression. Maize cell suspensions, however, cannot be synchronized completely. Therefore, we used partially synchronized transgenic cell suspension lines to study expression from the MSV promoters. These experiments indicated that the $C P$ and $\mathrm{C}$-sense promoters were expressed at slightly different points of the cell cycle. Whereas the MSV $C P$ ("late gene") promoter is active in the early G2 phase (and some expression is seen in the $\mathrm{S}$ phase), the $\mathrm{C}$-sense promoter is active in the early $\mathrm{S}$ phase, before the start of histone $H 4$ transcription, and is reactivated in the late G2 phase. The difference in the expression timing from these promoters is consistent with the functions of the MSV gene products. For example, the CP is required for encapsidation of MSV DNA and systemic infection (Liu et al. 1997) and thus is not needed in the early stages of MSV replication. In contrast, the relatively high level of expression from the $\mathrm{C}$-sense promoter by early $\mathrm{S}$ phase ( $2 \mathrm{~h}$ after removal of hydroxyurea) (Fig. 5B) could result in the REPA or REP proteins being produced prior to the detection of host-cellular DNA synthesis in infected cells. The REPA protein binds to retinoblastoma-like protein, thereby potentially releasing factors regulating the transition from the G1 to $\mathrm{S}$ phase of the cell cycle. Thus, the early production of REPA could facilitate the manipulation of the host cell cycle. Our experiments cannot identify differential expression of

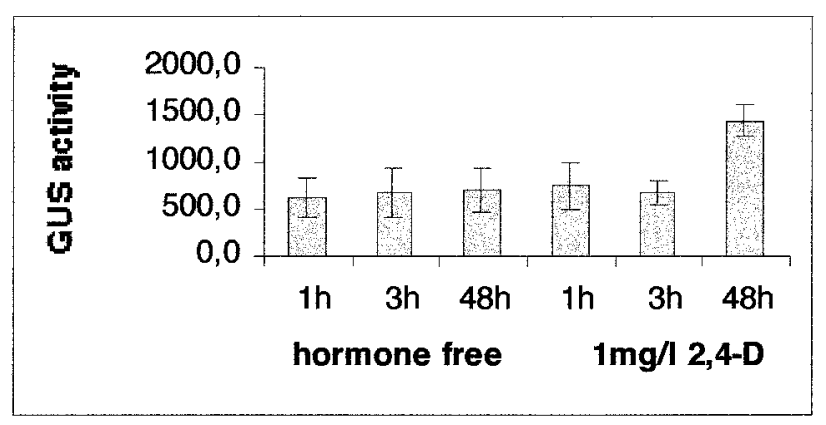

Fig. 3. The effect of 2,4-dichlorophenoxy acetic acid (2,4-D) on the expression of the prCP promoter in transformed maize suspension cells. Suspensions were incubated in the absence or the presence of 2,4-D for the periods indicated. The mean of three independent measurements is presented for each sample. Bars represent the standard deviation from the mean. $\beta$-glucuronidase activity is presented as pmol 4-methyl umbelliferone per $\mathrm{mg}$ of protein per h. 
REP and REPA, but REP is necessary to initiate the rolling circle replication of all geminiviruses (Desbiez et al. 1995; Gutierrez 2000; Schalk et al. 1989), which is likely to be accomplished during $\mathrm{S}$ phase.

The requirement for the REP (or REPA) protein in the G2 phase of the cell-division cycle is more perplexing. One possibility is that the REP protein may actively interfere with the progression through the G2 phase, thereby locking infected plant cells into S phase (Nagar et al. 1995). This proposition is consistent with the report that cell division could not be detected in TGMV-infected leaf cells and that transgenic tobacco cells expressing the TGMV REP (AC1-AL1 protein) significantly increased doubling times in suspension culture (Nagar et al. 1995). Interference with cell-cycle progression has been reported for mammalian DNA tumor viruses such as SV40, which also modify the host cell cycle in order to create an environment suitable for viral replication. Progression through $\mathrm{G} 2$ into the $\mathrm{M}$ phase requires the activation of cell-cycledependent protein kinases such as cdc2, and the SV40 large T antigen can interfere with $\mathrm{G} 2$ transit by preventing the activation of cyclin $\mathrm{B}-\mathrm{cdc} 2$ complexes during lytic infection



B

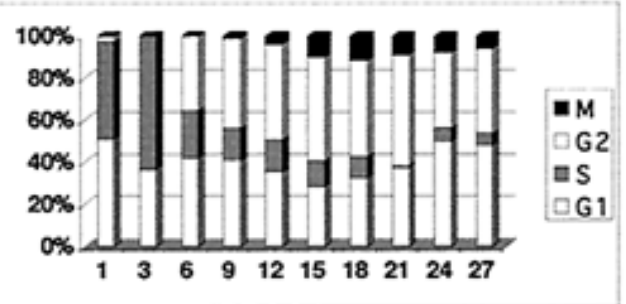

Fig. 4. Cell-cycle, phase-dependent expression of the prCP promoter in partially synchronized transgenic maize cells. A, Northern blot hybridization analysis of histone $4(H 4)$, cyclin B1, and coat protein promoterdirected transcript levels in partially synchronized maize cells ( $\mathrm{prCP}$ activity was analyzed by Northern blot hybridization with a $\beta$ glucuronidase-specific probe). Northern analysis was carried out with full-length cDNA probes. Ribosomal RNAs, shown as a control for RNA loading levels, were visualized by staining with ethidium-bromide. Samples were taken at the times shown below the autoradiographs and represent the hours after removal of hydroxyurea. B, Cell-cycle progression of maize cells transformed with prCP following hydroxyurea removal, as shown by the relative frequency of nuclei in G1 (2C), G2 (4C), and $\mathrm{S}(2 \mathrm{C}<\mathrm{S}>4 \mathrm{C})$ phase. Nuclei were isolated from cells of the partially synchronized cultures used to obtain the data shown in $\mathbf{A}$. The DNA content of the nuclei from $1 \times 10^{4}$ cells was determined by flow cytometry of ethidium bromide-stained nuclei. Mitotic indices were determined in parallel by counting approximately $1 \times 10^{3} 4,6-$ diamidine-2-phenylindole-stained nuclei under a fluorescent microscope. Percentage figures (left) allow estimation of the proportion of cells at each stage of the cell cycle.
(Scarano et al. 1994). The availability of additional cell-cycle marker probes such as PCNA, CDK, and cyclin genes (or antibodies against proteins present only at specific points in the cell cycle) should allow for further characterization of the molecular mechanisms by which the cell cycle is manipulated in geminivirus-infected plant cells.

\section{MATERIALS AND METHODS}

\section{Protoplast culture.}

Maize protoplasts were isolated from cell suspension cultures of line HE/89 and cultured essentially as described by Mórocz et al. (1990).

\section{Plasmid construction.}

The pMB105 plasmid encoding the genome of the severe variant of the Nigerian strain of MSV (MSV-Ns), described by Boulton et al. (1991), was used for polymerase chain reaction (PCR) amplification of different regions of MSV.

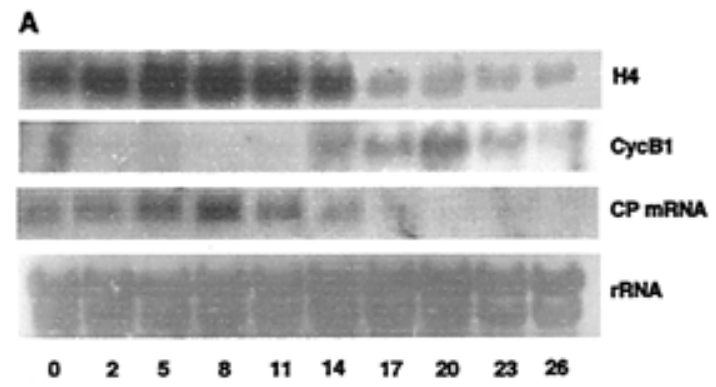

$\mathbf{B}$

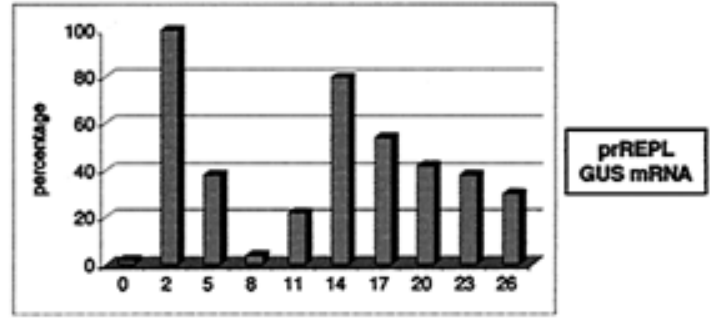

C



Fig. 5. Expression from the MSV coat protein $(C P)$ and $\mathrm{C}$-sense promoters present on the prREPL construct. Partially synchronized maize cells transformed with prREPL were used to examine MSV bidirectional transcription. A, Northern blot hybridization analysis and cell sampling was carried out as described in Figure 4, except that a $C P$ probe was used to detect the $C P$ transcript. $\mathbf{B}$, Histogram representing expression from the $\mathrm{C}$-sense promoter prREPL, assessed by phosphorimager quantification of hybridization to $\beta$-glucuronidase-specific mRNA isolated from the samples described in A. C, Cell-cycle progression of cells after hydroxyurea removal. The nuclei were isolated from aliquots of the same cell samples used to produce the data in $\mathbf{A}$ and $\mathbf{B}$, and were processed as described in Figure 4B. 
To produce the prCP (MSV V-sense, $C P$ gene promoter) construct, the $C P$ promoter region of MSV was amplified with the forward (F; 5'-CGGAATTCGACGACGGAGGTTGAG$\left.3^{\prime}\right)$ and reverse (5'-CGAAGCTTGAATGCTTATCCCGTG-3') primers and the PCR technique. The forward and reverse primers contained EcoRI and HindIII restriction sites, respectively. The PCR product was cloned into pBluescript (pBS+, Stratagene, La Jolla, CA, U.S.A.), to produce MSV-pBS, and sequenced. The sequenced fragment was cloned subsequently into the EcoRI-HindIII sites of pLP100 (Szczyglowski et al. 1994). To create the MSV C-sense, gene-promoter construct prREPS, the promoter sequence was released from MSV-pBS by HindIII and $\mathrm{XbaI}$ digestion and inserted into pLP100. The prCP and the prREPS contain the MSV sequences between coordinates 2,379 and 295. The prREPL plasmid contained most of the MSV genome (coordinates 2,379 to 1,644) in front of the GUS gene, and only the MSV REPA gene sequence was missing. To generate this construct, we used primer $\mathrm{F}$ and a reverse primer (5'-GCGAATTCATGGATGGATTCTGTATC$\left.3^{\prime}\right)$ containing an EcoRI site. The PCR product was cloned into $\mathrm{pBS}+$ and sequenced. The EcoRI fragment encompassing the MSV sequence was ligated to pLP100.

\section{Protoplast isolation, transformation and regeneration.}

Maize protoplasts were isolated from suspension cultures (Omirulleh et al. 1993). Aliquots of $0.3 \mathrm{ml}$ of washed protoplasts $\left(1\right.$ to $\left.3 \times 10^{6}\right)$ in $\mathrm{MaCa}\left(0.2 \mathrm{M}\right.$ mannitol; $0.08 \mathrm{M} \mathrm{CaCI}_{2}$; and $0.1 \%$ morpholineethanesulfonic acid, $\mathrm{pH}$ 6.0) were distributed into glass tubes. Following the addition of 10 to $30 \mu \mathrm{g}$ of plasmid DNA dissolved in sterile water, $0.3 \mathrm{ml}$ of $40 \%$ polyethylene glycol $\left(\mathrm{M}_{\mathrm{r}} 4000\right)$ dissolved in $\mathrm{F}$ medium (Krens et al. 1982) was added, and the contents of the tube immediately mixed. After incubation for $20 \mathrm{~min}$ at room temperature, the mixture was diluted by three sequential additions of $2 \mathrm{ml}$ of $\mathrm{MaCa}$. Protoplasts pelleted by centrifugation were resuspended in protoplast culture medium pp N6M/89 (Mórocz et al. 1990) at a density of $1 \times 10^{6}$ per ml. Maintenance and regeneration of transformed calli were carried out as described by Mórocz et al. (1990).

\section{2,4-D treatment of plantlets and suspension cultures.}

Aliquots of maize suspension cultures transformed with the prCP construct (lines prCP [2], [4], and [5]) were transferred to N6M liquid medium (Mórocz et al. 1990), lacking or supplemented with 0.2 or $1 \mathrm{mg}$ of 2,4-D per liter. Samples were taken at 1,3 , and $48 \mathrm{~h}$ after hormone addition.

Plantlets were transferred to plates containing similarly supplemented N6 medium, and sampling was done 3 days after addition of 2,4-D.

\section{Cell synchronization and analysis.}

Suspension cells were synchronized by the method described by Peres et al. (1999), except that the final concentration of hydroxyurea was $5 \mathrm{mM}$. Synchronized cells were resuspended in five to 10 volumes of conditioned medium. Synchrony was monitored by mitotic index and nuclear DNA content analysis in samples taken before and after the washing procedure as well as every 2 to $3 \mathrm{~h}$ subsequently. Cells were fixed, stained with 4,6-diamidine-2-phenylindole (DAPI), and examined by fluorescence microscopy, as described by Peres et al. (1999). For each sample, 10 to $20 \times 10^{3}$ nuclei were stained with ethidium-bromide and used for flow cytometric determination of the DNA content, as described previously (Peres et al. 1999). RNA extraction and Northern blot hybridization analysis of the cell samples was carried out as described by Monroy et al. (1993). For Northern analysis, $20 \mu \mathrm{g}$ of sample RNA was loaded.

\section{Analysis of GUS activity.}

Fluorometric GUS assays were performed, as described by Jefferson et al. (1987). Freshly prepared callus lysate was used, and each sample was assayed in duplicate. In order to express GUS activity in relation to the protein content, the total protein concentration of each lysate was determined by the Bradford method with a Bio-Rad protein estimation kit (Bio-Rad Laboratories, Hercules, CA, U.S.A.). For histochemical assays, roots were rinsed with $100 \mathrm{mM}$ sodium phosphate buffer, $\mathrm{pH} 7.2$, and incubated overnight in the presence of $2 \mathrm{mM}$ chromogenic substrate X-Gluc (5-bromo-4chloro-3-indolyl- $\beta$-D-glucuronide). Roots were cleared (Beeckman and Engler 1994) with lactophenol (chloralhydrate-phenol-lactic acid; 2:1:1) reagent. Cellular localization of GUS expression was analyzed in hand-sectioned material (approximate thickness: 0.5 to $1 \mathrm{~mm}$ ) by light microscopy. Shoots and leaves also were tested for expression.

\section{BrdU-labeling and visualization of incorporated BrdU with anti-BrdU antibody.}

All procedures were carried out at room temperature. Maize roots were transferred into N6M medium containing a 100fold-diluted $5 \mathrm{mM}$ BrdU labeling mixture (Amersham International, Little Chalfont, Buckinghamshire, U.K.) and incubated for $12 \mathrm{~h}$. The samples were fixed with $4 \%$ paraformaldehyde for $1 \mathrm{~h}$, and 0.5 - to 1 -mm sections were made by hand. Sections were soaked in $0.2 \mathrm{M} \mathrm{HCl}$ for $20 \mathrm{~min}$ to denature the DNA. After neutralization with phosphate-buffered saline, the samples were incubated with mouse anti-BrdU monoclonal antibody (Amersham) for $2 \mathrm{~h}$, then incubated with fluorescein isothiocyanate (FITC)-conjugated secondary antibody (goat anti-mouse immunoglobulin G (Biosource, Camarillo, CA, U.S.A.) for $30 \mathrm{~min}$ and stained with $100 \mathrm{ng}$ of DAPI per $\mathrm{ml}$. Zeiss Axiovert $135 \mathrm{M}$ fluorescence microscope equipped with Laser scanning and detection facilities (Carl Zeiss, Thornwood, NY, U.S.A.) was used for detection. Confocal observations of 50 roots were made with Zeiss Plan NeoFluor pol objectives connected to a CCD camera and specific filters for DAPI and FITC. Images were colored artificially by combining red (for DAPI) and green (FITC) channels.

\section{LITERATURE CITED}

Abouzid, A. M., Barth, A., and Jeske, H. 1988. Immunogold labeling of the Abutilon mosaic virus in ultrathin section of epoxy resin embedded leaf tissue. J. Ultrastruct. Mol. Struct. Res. 99:38-47.

Alizadeh, S., and Mantell, S. H. 1991. Early cellular events during direct somatic embryogenesis in cotyledon explants of Solanum aviculare For. Ann. Bot. 67:257-263.

Aloni, R. 1987. The induction of vascular tissues by auxin. Pages 363374 in: Plant Hormones and Their Role in Plant Growth and Development P. J. Davies, ed. Kluwer Academic Publishers, Dordrecht, The Netherlands.

Atanassova, R., Flénet, M., Gigot, C., and Chaubet, N. 1998. Functional analysis of the promoter region of a maize (Zea mays L.) H3 histone gene in transgenic Arabidopsis thaliana. Plant Mol. Biol. 37:275-285. 
Beeckman, T., and Engler, G. 1994. An easy technique for the clearing of histochemically stained plant tissue. Plant Mol. Biol. Rep. 12:3742

Benfey, P. N., Ren, L., and Chua, N.-H. 1990. Tissue-specific expression from CaMV 35S enhancer subdomains in early stages of plant development. EMBO J. 9:1677-1684.

Bouchez, D., Tokhuisa, J. G., Llewellyn, D. J, Dennis, E. S., and Ellis, J. G. 1989. The ocs-element is a component of the promoters of several T-DNA and plant viral genes. EMBO J. 8:4197-4204.

Boulton, M. I., Steinkellner, H., Donson, J., Markham, P. G., King, D. I. and Davies, J. W. 1989. Mutational analysis of the virion-sense genes of maize streak virus. J. Gen. Virol. 70:2309-2323.

Boulton, M. I., King, D. I., Donson, J., and Davies, J. W. 1991. Point substitutions in a promoter-like region and the V1 gene affect the host range and symptoms of maize streak virus. Virology 183:114-121.

Boulton, M. I., Pallaghy, C. K., Chatani, M., MacFarlane, S., and Davies, J. W. 1993. Replication of maize streak virus mutants in maize protoplasts: Evidence for a movement protein. Virology 192:85-93

Cleland, R. 1987. Auxin and cell elongation. Pages 132-148 in: Plant Hormones and Their Role in Plant Growth and Development. P. J. Davies, ed. Kluwer Academic Publishers, Dordrecht, The Netherlands.

Cline, M. G. 1994. The role of hormones in apical dominance: New approaches to an old problem in plant development. Physiol. Plant. 90:230-237.

Dekker, E. L., Woolston, C. J., Xue, Y., Cox, B., and Mullineaux, P. M. 1991. Transcript mapping reveals different expression strategies for the bicistronic RNAs of the geminivirus wheat dwarf virus. Nucleic Acids Res. 19:4075-4081.

Desbiez, C., David, C., Mettouchi, A., Laufs, J., and Gronenborn, B. 1995. Rep protein of tomato yellow leaf curl geminivirus has an ATPase activity required for viral DNA replication. Proc. Natl. Acad. Sci. USA 92:5640-5644.

Dickinson, V. J., Halder, J., and Woolston, C. J. 1996. The product of maize streak virus ORF V1 is associated with secondary plasmodesmata and is first detected with the onset of viral lesions. Virology 220:51-59.

Dudits, D., Bögre, L., Bakó, L., Dedeoglu, D., Magyar, Z., Kapros, T., Felföldi, F., and Györgyey, J. 1993. Key component of cell cycle control during auxin-induced cell division. Pages 111-131 in: Molecular and Cell Biology of the Plant Cell Cycle. Kluwer Academic Publishers, Dordrecht, The Netherlands.

Evans, M. L. 1984. Functions of hormones at the cellular level of organization. Pages 23-79 in: Encyclopedia of Plant Physiology, Vol. 10. A. Pirson and M. H. Zimmerman, eds. Springer-Verlag, Berlin.

Fenoll, C., Black, D. M., and Howell, S. H. 1988. The intergenic region of maize streak virus contains promoter elements involved in rightward transcription of the viral genome. EMBO J. 7:1589-1596.

Fenoll, C., Schwarz, J. J., Black, D. M., Schneider, M., and Howell, S. H. 1990. The intergenic region of maize streak virus contains a GCrich element that activates rightward transcription and binds maize nuclear factors. Plant Mol. Biol. 15:865-877.

Gooding, P. S., Batty, N. P., Goldsbrough, A. P., and Mullineaux, P. M. 1999. Plant cell-directed control of virion sense gene expression in wheat dwarf virus. Nucleic Acids Res. 27:1709-1718.

Gutierrez, C. 2000. DNA replication and cell cycle in plants: Learning from geminiviruses. EMBO J. 19:792-799.

Guzzo, F., Baldan, B., Levi, M., Sparvoli, E., Loschiavo, F., Terzi, M., and Mariani, P. 1995. Early cellular events during induction of carrot explants with 2,4-D. Protoplasma 185:28-36.

Hanley-Bowdoin, K., Settlage, S. B., Orozco, B. M., Nagar, S., and Robertson, D. 1999. Geminiviruses: Models for plant DNA replication, transcription, and cell cycle regulation. Crit. Rev. Plant Sci. 18:71-106.

Hong, Y., Saunders, K., Hartley, M., and Stanley, J. 1996. Resistance to geminivirus infection by virus-induced expression of dianthin in transgenic plants. Virology 220:119-127.

Jefferson, R. A., Kavanagh T. A., and Bevan M. W. 1987. GUS fusions: $\beta$-glucuronidase as a sensitive and versatile gene fusion marker in higher plants. EMBO J. 6:3901-3907.

Kotlitzky, G., Boulton, M. I., Pitaksutheepong, C., Davies, J. W., and Epel, B. 2000. Intracellular and intercellular movement of maize streak geminivirus V1 and V2 proteins transiently expressed as green fluorescent protein fusions. Virology 274:32-38.
Krens, F. A., Molendijk, L., Wullems, G. J., and Schilperoort, R. A. 1982. In vitro transformation of plant protoplasts with Ti-plasmid DNA. Nature 296:72-74.

Lazarowitz, S. G. 1988. Infectivity and complete nucleotide sequence of the genome of a South African isolate of maize streak virus. Nucleic Acids Res. 16:229-249.

Lazarowitz, S. G. 1992. Geminiviruses: Genome structure and genome function. Crit. Rev. Plant Sci. 11:327-349.

Lazarowitz, S. G., Pinder, A. J., Damsteegt, V. D., and Rogers, S. G. 1989. Maize streak virus genes essential for systemic spread and symptom development. EMBO J. 8:1023-1032.

Liu, H., Boulton, M. I., and Davies, J. W. 1997. Maize streak virus coat protein binds single-and double-stranded DNA in vitro. J. Gen. Virol. 78:1265-1270.

Liu, H., Boulton, M. I., Thomas, C. L., Prior, D. A. M., Oparka, K. J., and Davies, J. W. 1999. Maize streak virus coat protein is karyophyllic and facilitates nuclear transport of viral DNA. Mol. Plant-Microbe Interact. 12:894-900

Liu, H., Boulton, M. I., Oparka, K. J., and Davies, J. W. 2001. Interaction of the movement and coat proteins of Maize streak virus: Implications for the transport of viral DNA. J. Gen. Virol. 82:35:44.

Lucy, A. P., Boulton, M. I., Davies, J. W., and Maule, A. J. 1996. Tissue specificity of Zea mays infection by maize streak virus. Mol. PlantMicrobe Interact. 9:22-31.

Mazithulela, G., Sudhakar, D., Heckel, T., Mehlo, L., Christou, P., Davies, J. W., and Boulton, M. I. 2000. The maize streak virus coat protein transcription unit exhibits tissue-specific expression in transgenic rice. Plant Sci. 155:21-29.

Monroy, A. F., Sarhan, F., and Dhindsa, R. S. 1993. Cold-induced changes in freezing tolerance, protein phosphorylation, and gene expression: Evidence for a role of calcium. Plant Physiol. 102:12271235.

Mórocz, S., Donn, G., Németh, J., and Dudits, D. 1990. An improved system to obtain fertile regenerants via maize protoplasts isolated from a highly embryogenic suspension culture. Theor. Appl. Genet. 80:721-726.

Morozov, S. Y., Merits, A., and Chernov, B. K. 1994. Computer search of transcription control sequences in small plant virus DNA reveals a sequence highly homologous to the enhancer element of histone promoters. DNA Seq. 4:395-397.

Morris-Krsinich, B. A. M., Mullineaux, P. M., Donson, J., Boulton, M. I., Markham, P. G., Short, M. N., and Davies, J. W. 1985. Bidirectional transcription of maize streak virus DNA and identification of the coat protein gene. Nucleic Acids Res. 13:7237-7256.

Mullineaux, P. M., Donson, J., Morris-Krsinich, B. A. M., Boulton, M. I., and Davies, J. W. 1984. The nucleotide sequence of maize streak virus DNA. EMBO J. 3:3063-3068.

Mullineaux, P. M., Guerineau, F., and Accotto, G.-P. 1990. Processing of complementary sense RNAs of Digitaria streak virus in its host and in transgenic tobacco. Nucleic Acids Res. 18:7259-7265.

Nagar, S., Pedersen, T. J., Carrick, K. M., Hanley-Bowdoin, L., and Robertson, D. 1995. A geminivirus induces expression of a host DNA synthesis protein in terminally differentiated plant cells. Plant Cell 7:705-719.

Omirulleh, S., Ábrahám, M., Golovkin, M., Stefanov, I., Karabaev, M. K., Mustárdy, L., Mórocz, S., and Dudits, D. 1993. Activity of a chimeric promoter with the doubled CaMV $35 \mathrm{~S}$ enhancer element in protoplast-derived cells and transgenic plants in maize. Plant Mol. Biol. 21:415-428.

Padidam, M., Maxwell, D. P., and Fauquet, C. M. 1997. A proposal for naming geminiviruses. Arch. Virol. 142:2553-2561.

Palmer, K. E., and Rybicki, E. P. 1998. The molecular biology of mastreviruses. Adv. Virus Res. 50:183-234.

Peres, A., Ayaydin, F., Nikovics, K., Gutiérrez, C., Horváth, V. G. Dudits, D., and Fehér, A. 1999. Partial synchronisation of cell division in cultured maize (Zea mays L.) cells: Differential cyclin, cdc2, histone and retinoblastoma transcript accumulation during the cell cycle. J. Exp. Bot. 50:1373-1379.

Ruiz-Medrano, R., Guevara-Gonzalez, R. G., Arguella-Astorga, G. R., Monsalve-Fonnegra, Z., Herrera-Estrella, L. R., and RiveraBustamante, R. F. 1999. Identification of a sequence element involved in AC2-mediated transactivation of the pepper huasteco virus coat protein gene. Virology 253:162-169.

Rushing, A. E., Sunter, G., Gardiner, W. E., Dute, R. R., and Bisaro, D. 
M. 1987. Ultrastructural aspects of tomato golden mosaic virus infection in tobacco. Phytopathology 77:1231-1236.

Sanderfoot, A. A., and Lazarowitz, S. G. 1996. Getting it together in plant virus movement: Cooperative interactions between bipartite geminivirus movement proteins. Trends Cell Biol. 6:353-358.

Scarano, F. J., Laffin, J. A., Lehman, J. M., and Friedrich, T. D. 1994. Simian virus 40 prevents activation of M-phase-promoting factor during lytic infection. J. Virol. 68:2355-2361.

Schalk, H.-J., Matzeit, V., Schiller, B., Schell, J., and Gronenborn, B. 1989. Wheat dwarf virus, a geminivirus of graminaceous plants needs splicing for replication. EMBO J. 8:359-364.

Sunter, G., and Bisaro, D. M. 1997. Regulation of a geminivirus coat protein promoter by AL2 protein (TrAP): Evidence for activation and derepression mechanisms. Virology 232:269-280.

Szczyglowski, K., Szabados, L., Fujimoto, S. Y., Silver, D., and De Bruijn, F. J. 1994 Site-specific mutagenesis of the nodule-infected cell expression (NICE) element and the AT-rich element ATRE-BS2* of the Sesbania rostrata leghemoglobin glb3 promoter. Plant Cell 6:317332

Terada, R., Nakayama, T., Iwabuchi, M., and Shimamoto, K. 1995. A type I element composed of the hexamer (ACGTCA) and octamer (CGCGGATC) motifs plays a role(s) in meristematic expression of a wheat histone $\mathrm{H} 3$ gene in transgenic rice plants. Plant Mol. Biol. 27:17-26.

Webster, B. D., and Radin, J. W. 1972. Growth and development of cultured radish roots. Am. J. Bot. 59:744-751.

Wright, E. A., Heckel, T., Groenendijk, J., Davies, J. W., and Boulton, M. I. 1997. Splicing features in maize streak virus virion- and complementary-sense gene expression. Plant J. 6:1285-1297.

Zhan, X., Richardson, K. A., Haley, A., and Morris, B. A. M. 1993. The activity of the coat protein promoter of chloris striate mosaic virus is enhanced by its own and C1-C2 products. Virology 193:498-502. 